\title{
The Effect of Glutathione Addition in Diluent Semen on Ram Spermatozoa Quality
}

\author{
Muthiah Syafitri ${ }^{1}$, Teguh Ari Prabowo ${ }^{1}$, Pradita Iustitia Sitaresmi ${ }^{1}$, Lies Mira \\ Yusiati $^{2}$, Sigit Bintara ${ }^{1}$ and Diah Tri Widayati ${ }^{1 *}$ \\ ${ }^{1}$ Department of Animal Breeding and Reproduction, Faculty of Animal Science, UGM, Indonesia \\ ${ }^{2}$ Department of Animal Nutrition and Feed Science, Faculty of Animal Science, UGM, Indonesia \\ "Corresponding author.Email: widayati@ugm.ac.id
}

\begin{abstract}
Cryopreservation of ram sperm reduces sperm motility and breaks sperm membrane integrity due to free radicals developed by reactive oxygen species (ROS). Moreover, it provokes cryodamage and deteriorates sperm quality. This study investigated the effect of glutathione addition as an antioxidant agent on the quality of local ram spermatozoa. The impacts of glutathione additions were observed in five different concentrations (control, $0.5 \mathrm{mM}, 1 \mathrm{mM}$, and 1.5 $\mathrm{mM}$ or treatment P0-P4); the extender used to dilute the semen of two rams was andromed diluents. This research examined factors including the quality of fresh sperm, sperm motility, and membrane integrity after chilled. The data in this research was analyzed using one-way ANOVA to determine the effect of glutathione addition between the control and treatment groups. The outcomes demonstrated that adding glutathione significantly $(p<0.05)$ enhanced motility and membrane integrity after stored in cold storage for 48 hours. In comparison with the control, the P1 concentration generated the best results in terms of ensuring the integrity of ram spermatozoa after processing. Glutathione concentration of $0.1 \mathrm{mM}(\mathrm{P} 1)$ showed the best motility and membrane integrity at 0 hours and 48 hours cold storage $(82.50 \pm 0.92$ versus $65.35 \pm 1.80 \%$ and $87.50 \pm 0.50$ versus $68.75 \pm 1,83 \%$. In conclusion, the addition of glutathione affected the quality of local sheep spermatozoa after cooling. We obtain the best results of membrane motility and integrity at the glutathione level of $0.1 \mathrm{nM}$.
\end{abstract}

Keywords: andromed diluent, antioxidant agent, motility, membrane integrity, ROS, semen preservation

\section{INTRODUCTION}

Indonesia has an abundant small ruminants population, dominated by the commodity of sheep [1]. Differing from the sheep raised in a sub-tropical area, the sheep in the tropics like Indonesia were not significantly affected by photoperiod. Some problems usually occur in Indonesia are heat stress and feed availability and quality. These problems can lower the sheep's reproductive performances such as a higher score of services per conception (s/c), longer kidding interval, or reduced number of twins or triplet kids [2]. As a consequence of these instances, a research study should indeed increase the capacity of the breeding flock and the reproductive efficiency [3]. Reproductive technologies for small ruminants, such as in vitro fertilization (IVF), have been the most effective approach reproductive efficiency [4], embryo transfer (ET) [3], or artificial insemination (AI) [5].

In Indonesia, AI is a reproductive technique commonly used to elevate sheep reproductive efficiency [6] and sperm cryopreservation is a crucial tool either in AI or IVF [7]. Cryopreservation helps the spermatozoa live longer and prevents the dispersion of pathogens [8] However, during the method, free radicals such as lipid peroxidation and reactive oxygen species (ROS) were also developed, exacerbating the sperm seminal plasma to be eliminated [9], reduces the viability of spermatozoa, lowers spermatozoa survival, or impairs 
the fertilization potential [10] by redox deregulation [7]. Though since there own membrane plasma contains a high concentration of polyunsaturated fatty acids, ram spermatozoa were indeed highly porous to oxidative degradation [11]. To overcome this limitation, the integration of exogenous antioxidants into the cryopreservation process primarily accelerated cell viability, as illustrated by a higher percentage of motility and membrane plasma [12].

To preserve sperm viability in ram, antioxidant agents including catalase (CAT), glutathione (GSH), glutathione peroxidase (GPx), or superoxide dismutase (SOD) were being used as defensive system agents against ROS and LPO [13]. In a recent study, the supplementations of GSH in semen from farm animals such as canine [14], sow [15], bull or bovine [16], rabbits [17], rooster[18] increased the quality of postthawing sperm by increasing motility and membrane integrity [13]. Glutathione had a role to protect cells from oxidative effects by detoxification mechanism [19]. This study determined the effects of various levels of GSH supplementation in diluent ram semen on motility and membrane integrity levels.

\section{MATERIAL AND METHOD}

\subsection{Animals and chemicals}

Two mature local ram reproductive tracts were retained under standard field and laboratory conditions and carried out in compliance with university guidelines. The chemicals used were diluent liquid andromed ${ }^{\circledR}$ (Minitube, Germany), exogenous glutathione (GSH) (Merck, Germany), eosin (Sigma-Aldrich, USA), liquid nitrogen, and aquabidest.

\subsection{Semen collection and initial evaluation}

Semen was collected twice a week for four weeks using an artificial vagina and was initially assessed for sperm quality. Semen have normal color, $0.8 \pm 0.2 \mathrm{~mL}$ volume, $>80 \%$ motility and viability and $3600 \pm 120.21$ $10 \% \mathrm{~mL}$ concentration, $<10 \%$ abnormality (Table 1 ).

\subsection{Post Chilled Semen evaluation}

The sperm ejaculates were pooled to minimize the sample errors. The pooled sperm was first diluted 1:4 with andromed. The diluted samples were split into four aliquots according to GSH concentration (P0 $0 \mathrm{mM}$; P1:0.5 mM; P2: $1.0 \mathrm{mM}$; and P3:1.5 mM). The samples were kept in a cold cabinet for $48 \mathrm{~h}$ at $5^{\circ} \mathrm{C}$ and monitored for sperm motility and membrane integrity. The sperm motility had been ascertained by arranging $10 \mathrm{~L}$ of diluent mixed with $\mathrm{NaCl}(1: 4)$ on the microscope and high - pressure homogenization it (Olympus $\mathrm{CH}$ 20). The picture was captured from ten fields at a magnification of $100 \times 400$, and the scores ranged from 0 to $100 \%$ with a $5 \%$ scale [20].

Giemsa staining procedure at $37^{\circ} \mathrm{C}$ was used for acrosomal integrity. A sample of 200 spermatozoa were recorded per sample using an Olympus $\mathrm{CH} 20$ light microscope to distinguish between reacted and nonreacted spermatozoa. Sperm with a damaged acrosome generated a strong purple color, whereas sperm that did not react discharged a light violet color.

Table 1. Initial evaluation on fresh local ram semen before the treatment

\begin{tabular}{|l|c|}
\hline \multicolumn{1}{|c|}{ Parameter } & Mean \pm SD \\
\hline Color & Normal \\
\hline $\mathrm{pH}$ & $6.9 \pm 0.1$ \\
\hline Volume $(\mathrm{ml})$ & $0.80 \pm 0.2$ \\
\hline Mass movement & +++ \\
\hline Concentration $\left(10^{6}\right)$ & $3600 \pm 120.21$ \\
\hline Motility $(\%)$ & $81.25 \pm 1.0$ \\
\hline Viability $(\%)$ & $88.02 \pm 3.15$ \\
\hline Abnormality $(\%)$ & $9.89 \pm 2.97$ \\
\hline
\end{tabular}

\subsection{Statistical analyzed}

The findings were tabulated as mean standard deviation (SD). The statistically significant difference of the mean values was determined using one-way ANOVA followed by Duncan's post hoc test with $p<0.05$ as the statistically significant criterion.

\section{RESULTS AND DISCUSSION}

Mostly, cryopreservation in semen generates a high production of ROS and triggers various stages of cryodamage that can affect sperm quality and fertility [21], [22]. To mitigate ROS, seminal plasma spermatozoa usually produce anti-oxidant enzymes such as glutathione peroxide (GSH-Px), superoxide dismutase (SOD), and catalase (CAT), as well as other enzymes to prevent cells from LPO, which could also be developed in the reproductive tract [23]. Pro and antioxidant systems are generally found in a balanced state to redox deregulation ROS and prevent pathological processes [24]. The concentration of ROS, on the other hand, was indeed outrageously high in the cryopreservation or refrigerator preservation method. As a consequence, the sperm membrane, which would be the primary organelle against ROS, was confined to cooling and freezing conditions [17]. Consequently, the addition of an exogenous antioxidant such as glutathione (GSH) is considered to maintain the quality of semen after diluent or undergo the preservation process [25]. Table 2 showed the initial and influence of different GSH concentrations on sperm motility and membrane 
Table 2. Effect of GSH addition in semen extender on local ram sperm motility and membrane integrity stored at $5^{\circ} \mathrm{C}$ for $48 \mathrm{~h}$

\begin{tabular}{|c|c|c|c|c|}
\hline \multirow{2}{*}{ GSH } & \multicolumn{2}{|c|}{ Motility (\%) } & \multicolumn{2}{c|}{ Membrane Integrity (\%) } \\
\cline { 2 - 4 } & $0 \mathrm{~h}$ & $48 \mathrm{~h}$ & $0 \mathrm{~h}$ & $48 \mathrm{~h}$ \\
\hline Control & $81.25 \pm 1.03^{\mathrm{a}}$ & $54.20 \pm 0.35^{\mathrm{Ab}}$ & $82.25 \pm 1.30^{\mathrm{a}}$ & $54.20 \pm 0.35^{\mathrm{Ab}}$ \\
\hline $0.5 \mathrm{mM}$ & $82.35 \pm 0.83^{\mathrm{a}}$ & $62.22 \pm 1.60^{\mathrm{Bb}}$ & $86.35 \pm 0.60^{\mathrm{a}}$ & $62.22 \pm 1.60^{\mathrm{Bb}}$ \\
\hline $1.0 \mathrm{mM}$ & $82.50 \pm 0.92^{\mathrm{a}}$ & $65.35 \pm 1.80^{\mathrm{Bb}}$ & $87.50 \pm 0.50^{\mathrm{a}}$ & $65.35 \pm 1.80^{\mathrm{Bb}}$ \\
\hline $1.5 \mathrm{mM}$ & $81.24 \pm 1.02^{\mathrm{a}}$ & $63.78 \pm 2.01^{\mathrm{Bb}}$ & $85.24 \pm 1.02^{\mathrm{a}}$ & $63.78 \pm 2.01^{\mathrm{Bb}}$ \\
\hline
\end{tabular}

Means in a row not sharing superscript show significant differences $(\mathrm{p}<0.05)$ for GSH addition $(\mathrm{ab}, \mathrm{AB})$

integrity more than a 48-hour prolonged storage. The degradation of sperm motility and membrane integrity were affected significantly $(p<0.05)$ by storage time. On the other hand, the sperm motility and membrane integrity were also influenced by the addition of concentration GSH during the storage time.

Preserving ram sperm decreased sperm fertilizing capacity due to motility alteration and harmed sperm membrane integrity. This study's reducing result was similar to the previous research on some other ram species [26]. However, when compared to the GSHadded diluent, the control treatment resulted in a significant reduction after 48 hours in the refrigerator. GSH is a tripeptide consisting of glutamic acids, cysteine, and glycine that is broadly disseminated in spermatozoa cells and plays a major role in intracellular ROS defensive system by supplying and uncovering a sulfhydryl group that immediately scurries free radicals [25]. This study revealed that adding a medium dose of GSH (1 mM) in extender for 48 hours optimized motility and membrane integrity, that was also supported by previous papers [17], [26], [27]. This result occurred because the antioxidant at $1 \mathrm{mM}$ concentration regained the equilibrium between the quantities of ROS generated and rifled, enabling the sperm metabolic rate to be retained [22]. The lower concentration was not found in the equilibrium point between the antioxidant and free radicals and made the motility of sperm decreased. The excessive ROS concentration was leading to superoxide formation and attacked plasma membrane cells which are rich in PUFA. Once the PUFA was disrupted, it created additional permeability of the sperm plasma membrane, enzyme inactivation, structural membrane damage to spermatic DNA, and degeneration of sperm motility, viability, and membrane integrity [28]. Higher concentration of GSH addition resulted in lower motility even though still higher than the control result, possibly caused by the swelling membrane sperm, mitochondria integrity, and reducing motility in the higher concentration [14]. Osmotic shock can lead to all sorts of sperm cellular damage, including plasma membrane obliteration and changes in intercellular signaling pathways [29]. Because of their high PUFA content, spermatozoa are susceptible to lipid peroxidation. These lipids can impair sperm motility, harm membrane integrity, and lead to detrimental effects such as fertility failure or induce apoptosis [30]. Exogenous GSH might indeed significantly decrease lipid peroxidation in sperm tails, leading to a significant progression in ram semen preservation [31]. The relatively low level of lipid peroxidation in the mitochondria, which seems required for sperm and flagellar movement and metabolism, might well be responsible for maintenance of motility and membrane integrity in GSH addition. GSH could indeed chemically interfere with many ROS and also acts as a cofactor for GSHPx, where it catalyzes the reduction of toxic $\mathrm{H} 2 \mathrm{O} 2$ and some other hydroperoxides [30]. Cysteine in GSH has to have a cryoprotective effect on axosome and mitochondrial functional integrity by enhancing post-thawed sperm motility and membrane integrity.

\section{CONCLUSION}

After cooling, the addition of glutathione influences the performance of local sheep spermatozoa. At the glutathione level of $0.1 \mathrm{nM}$. The study has collected the best results in terms of membrane motility and integrity.

\section{AUTHORS' CONTRIBUTION}

MS and DTW contemplated and execute the field work for data collection, also drafted the manuscript paper. MS, TAP, and PIS did the literature search and statistically analysis. All author executed the interpretation of analyzed data and revised the manuscript. The research design was supervised by DTW, SB, and LMY. All of the involved authors had reviewed and approved the final version of manuscript.

\section{ACKNOWLEDGMENTS}

The authors gratefully acknowledge Yogyakarta Traditional Farmers for providing the necessary infrastructure for these studies, as well as Universitas Gadjah Mada for partially funding the research through the Rekognisi Tugas akhir Grant (3134/UNI. P. III/DITLIT/PT/2021). 


\section{REFERENCES}

[1] Udo, J. M. S., and I. G. S. Budisatria. 2011. Fattailed sheep in Indonesia; an essential resource for smallholders. Trop. Anim. Health Prod. 43(7):1411-1418.

[2] Soares, F. N., M. E. F. Oliveira, L. C. P. Nakaghi, L. G. de Oliveira, M. A. R. Feliciano, F. B. B. de Oliveira, P. P. M. Teixeira, W. R. R. R. Vicente, C. Faturi, L. F. S. Rodrigues. 2015. Reproductive and productive performances of Santa Inês ewes submitted to breeding in different periods of the Amazonian humid tropical climate. Trop. Anim. Health Prod. 47(8): 1465-1471.

[3] Daly, J., H. Smith, H. A. McGrice, K. L. Kind, and W. H. E. J. van Wettere. 2020. Towards improving the outcomes of assisted reproductive technologies of cattle and sheep, with particular focus on recipient management. Animals. 10(2):1-15.

[4] Widayati, D. T., and M. Pangestu. 2020. Effect of follicle-stimulating hormone on Bligon goat oocyte maturation and embryonic development post in vitro fertilization. Vet. World. 13(11): 2443-2446.

[5] Gibbons, A. E., J. Fernandez, M. M. BrunoGalarraga, M. V. Spinelli, and M. I. Cueto, "Technical recommendations for artificial insemination in sheep. 2019. Anim. Reprod. 16(4): 803-809.

[6] Silveira, E., L. Bortolloti, and F. Morotti. 2013. Insemination of four cows per dose of frozen semen with a fixed-time artificial insemination protocol. Anim. Reprod, 10(2):124-126.

[7] Riesco, M. F., M. Alvares, L. A. Lopez, M. N. Montero, C. P. Martinez, R. M. Garrido, J. C. Boixo, P. de Paz, L. Anel. 2021.Multiparametric study of antioxidant effect on ram sperm cryopreservation-from field trials to research bench. Animals. 11(2):1-14.

[8] Buranaamnuay, K., P. Tummaruk, J. Singlor, H. Rodriguez-Martinez, and M. Techakumphu. 2009. Effects of straw volume and equex-STM $®$ on boar sperm quality after cryopreservation. Reprod. Domest. Anim. 44(1):69-73.

[9] Bustani, G. S., and F. H. Baiee. 2021. Semen extenders: An evaluative overview of preservative mechanisms of semen and semen extenders. Vet. World. 14(5):1220-1233.

[10] Bergstein-Galan, T. G., L. C. Bicudo, L. Rodello, R. R. Weiss, and S. D. Bicudo. 2018.Sperm membrane integrity and stability after selection of cryopreserved ovine semen on colloidal solutions.
Andrologia. 50(2):1-6.

[11] Allai, L., X. Druart, M. Öztürk, A. BenMoula, B. Nasser, and B. El Amiri. 2016. Protective effects of Opuntia ficus-indica extract on ram sperm quality, lipid peroxidation and DNA fragmentation during liquid storage. Anim. Reprod. Sci.175:1-9.

[12] Aliakbari, F., M. A. S. Gilani, F. Amidi, M. Baazm, M. Korouji, F. Izadyar, H. Yazdekhasti, M. Abbasi. 2016. Improving the Efficacy of Cryopreservation of Spermatogonia Stem Cells by Antioxidant Supplements. Cell. Reprogram. 18(2):87-95.

[13] Bucak, M. N., P. B. Tuncer, S. Sariozkan, N. Baspinar, M. Taspinar, K. Coyan, A. Bilgili, P. P. Akalin, S. Buyukleblebici, A. Aydos, S. Ilgaz, A. Sunguroglu, D. Oztuna. 2010. Effects of antioxidants on post-thawed bovine sperm and oxidative stress parameters: Antioxidants protect DNA integrity against cryodamage. Cryobiology. 61(3):248-253.

[14] Ogata, K., A. Sasaki, Y. Kato, A. Takeda, M. Wakabayashi, B. Sarentongloaga, M. Yamaguchi, A. Hara, R. Fukumori, Y. Nagao. 2015. FrozenThawed Canine Spermatozoa for Transcervical Inseminattion. J. Reprod Dev. 61(2):116-122.

[15] Estrada, E., J. E. Rodríguez-Gil, L. G. Rocha, S. Balasch, S. Bonet, and M. Yeste. 2014. Supplementing cryopreservation media with reduced glutathione increases fertility and prolificacy of sows inseminated with frozenthawed boar semen. Andrology. 2(1):88-99.

[16] Stradaioli, G., T. Noro, L. Sylla, and M. Monaci. 2007. Decrease in glutathione (GSH) content in bovine sperm after cryopreservation: Comparison between two extenders. Theriogenology. 67(7):1249-1255.

[17] Ahmad, E., Z. Naseer, and M. Aksoy. 2021. Glutathione supplementation in semen extender improves rabbit sperm attributes during refrigeration. World Rabbit Sci. 29(2):81-86.

[18] Masoudi, R., M. Sharafi, A. Z. Shaheh, H. Kohram, E. N. Amiri, H. Karimi, M. K. Motlagh, A. Shahverdi. 2018. Supplementation of extender with coenzyme Q10 improves the function and fertility potential of rooster spermatozoa after cryopreservation. Anim. Reprod. Sci. 198:193201.

[19] Dunning, S., A. Rehman, M. H. Tiebosch, R. A. Hannivoort, F. W. Haijer, J. Woudenberg, F. A. J. van den Heuvel, M. B. Homan. 2013. Glutathione and antioxidant enzymes serve complementary 
roles in protecting activated hepatic stellate cells against hydrogen peroxide-induced cell death. Biochim. Biophys. Acta - Mol. Basis Dis. 1832(12):2027-2034.

[20] Priyanto, L., R. I. Arifiantini, T. L. Yusuf. 2015. Deteksi Kerusakan DNA Spermatozoa Semen Segar dan Semen Beku Sapi Menggunakan Pewarnaan Toluidine Blue. J. Vet. 16(1):48-55.

[21] Martin-Hidalgo, D., M. J. Bragado, A. R. Batista, P. F. Oliveira, and M. G. Alves. 2019. Antioxidants and male fertility: From molecular studies to clinical evidence. Antioxidants. 8(4): 1-21.

[22] Len, J. S., W. S. D. Koh, and S. X. Tan. 2019. The roles of reactive oxygen species and antioxidants in cryopreservation. Biosci. Rep. 39(8): 1-25.

[23] Shi, L., T. Jin, Y. Hu, Z. Ma, H. Niu, and Y. Ren. 2020. Effects of reduced glutathione on ram sperm parameters, antioxidant status, mitochondrial activity and the abundance of hexose transporters during liquid storage at $5{ }^{\circ} \mathrm{C}$. Small Rumin. Res. 189: 106139.

[24] Aitken, R. J., and J. R. Drevet. 2020. The importance of oxidative stress in determining the functionality of mammalian spermatozoa: A twoedged sword. Antioxidants. 9(2):1-14.

[25] Petruska, P., M. Capcarova, and P. Sutovsky. 2014. Antioxidant supplementation and purification of semen for improved artificial insemination in livestock species. Turkish J. Vet. Anim. Sci. 38(6):643-652.

[26] Câmara, D. R., M. M. C. Mello-Pinto, L. C. Pinto, O. O. Brasil, J. F. Nunes, and M. M. P. Guerra. 2011. Effects of reduced glutathione and catalase on the kinematics and membrane functionality of sperm during liquid storage of ram semen. Small Rumin. Res. 100(1):44-49.

[27] Sarangi, A., P. Singh, M. Virmani, A. S. Yadav, S. Sahu, H. M. Ajithakumar, A. Kumari, A. P. Rath. 2017. Effect of antioxidants supplementation on the quality of Beetal buck semen stored at $4^{\circ} \mathrm{C}$. Vet. World. 10(10):1184-1188.

[28] de Jong, A. M. E., R. Menkveld, J. W. Lens, S. E. Nienhuis, and J. P. T. Rhemrev. 2014. Effect of alcohol intake and cigarette smoking on sperm parameters and pregnancy. Andrologia. 46(2):112-117.

[29] Dias, C., and J. Nylandsted. 2021. Plasma membrane integrity in health and disease: significance and therapeutic potential. Cell Discov. $7(4): 1-21$.

[30] Bansal, A. K., and G. S. Bilaspuri. 2011. Impacts of oxidative stress and antioxidants on semen functions. Vet. Med. Int. 2011: 686137.

[31] Banday, M. N., F. A. Lone, F. Rasool, M. Rashid, and A. Shikari. 2017. Use of antioxidants reduce lipid peroxidation and improve quality of crossbred ram sperm during its cryopreservation. Cryobiology. 74:25-30. 